PAPER

\title{
Clinical and economic results of bilateral subthalamic nucleus stimulation in Parkinson's disease
}

\author{
V Fraix, J-L Houeto, C Lagrange, C Le Pen, P Krystkowiak, D Guehl, C Ardouin, M-L Welter, \\ F Maurel, L Defebvre, A Rougier, A-L Benabid, V Mesnage, M Ligier, S Blond, P Burbaud, \\ B Bioulac, A Destée, P Cornu, P Pollak, on behalf of the SPARK Study Group
}

See end of article for authors' affiliations .....................

Correspondence to: Pierre Pollak, Department of Neurology, Grenoble University Hospital, BP 217,38043 Grenoble Cedex 9, France; Pierre. Pollak@ujf-grenoble.fr

Received 3 August 2005 Revised version received 5 October 2005

Accepted

15 November 2005
Background: High frequency stimulation of the subthalamic nucleus (STN) is an alternative but expensive neurosurgical treatment for parkinsonian patients with levodopa induced motor complications. Objective: To assess the safety, clinical effects, quality of life, and economic cost of STN stimulation. Methods: We conducted a prospective multicentre study in 95 consecutive Parkinson's disease (PD) patients receiving bilateral STN stimulation and assessed its effects over 12 months. A double blind randomised motor evaluation was carried out at 3 month follow up, and quality of life, self care ability, and predictive factors of outcome following surgery were assessed. The cost of PD was estimated over 6 months before and after surgery.

Results: The Unified Parkinson's Disease Rating Scale (UPDRS) motor score improved by $57 \%(p<0.0001)$ and activities of daily living improved by $48 \%(p<0.0001)$ at 12 month follow up. Double blind motor scoring improved by $51 \%$ at 3 month follow up $(p<0.0001)$. The total PD Quality of Life Questionnaire (PDQL-37) score improved by $28 \%(p<0.001)$. The better the preoperative motor score after a levodopa challenge, the better the outcome after STN stimulation. Five patients developed an intracerebral haematoma during electrode implantation with permanent after effects in two. The 6 month costs of PD decreased from $€ 10087$ before surgery to $€ 1673$ after surgery $(p<0.0001)$ mainly because of the decrease in medication. These savings allowed a return on the procedure investment, estimated at $€ 36904$ over 2.2 years.

Conclusions: STN stimulation has good outcomes with relatively low risk and little cost burden in PD patients with levodopa induced motor complications.
$\mathrm{P}$ arkinson's disease (PD) is one of the most common disabling neurological disorders and results in substantial burdens for patients, their families, and society in terms of increased health resource use and poorer quality of life. ${ }^{1-4}$ High frequency stimulation of the subthalamic nucleus (STN) is of growing interest for PD patients with levodopa induced motor complications. ${ }^{5-9}$ The variable benefit from this costly procedure raises the question of its economic consequences from a health insurance perspective. ${ }^{10-15}$

The SPARK Study Group conducted a prospective multicentre study in a large series of PD patients who received bilateral STN stimulation. The aims of this study were to measure the economic impact of STN stimulation, to evaluate its effects on motor symptoms, quality of life, cognition, and behaviour, and to determine predictive factors of outcome following surgery.

\section{METHODS \\ Patients}

A total of 110 consecutive patients from four French centres were selected according to previously described criteria. ${ }^{7}$ They all suffered from levodopa responsive PD complicated by motor fluctuations and dyskinesias. They were in general good health without dementia or psychiatric disturbances. ${ }^{16}{ }^{17}$ The study was approved by the ethics committee and all patients gave their written informed consent.

\section{Study design}

The design of the study is summarised in fig 1 .

\section{Clinical evaluation}

The patients were their own controls. Assessments were carried out before surgery, and at 3 and 12 months after surgery during planned visits. Clinical evaluations were performed in the off-medication condition after overnight fasting and in the on-medication condition during a levodopa challenge, using a suprathreshold levodopa dose defined as the usual first morning levodopa dose increased by $50 \mathrm{mg}$. After surgery, motor assessments were performed in four conditions (off medication and off stimulation, off medication and on stimulation, on medication and off stimulation, on medication and on stimulation). At the 3 month follow up, the levodopa challenge was carried out twice on separate days with central randomisation of the stimulation condition and double blind clinical assessment. Patients and examiners were asked to guess whether stimulation was switched on or off. The electrical parameters were set at least $\mathrm{l} \mathrm{h}$ before evaluation. No patient reported any symptoms that may have affected the blind assessment.

The effects of STN stimulation were evaluated using the Unified Parkinson's Disease Rating Scale (UPDRS). ${ }^{18}$ Patients completed a home diary. Cognitive functions were assessed using the Mattis Dementia Rating Scale for global cognitive assessment, the Grober and Buschke scale for evaluation of memory, and a 50 point frontal lobe dysfunction scale, including the Wisconsin card sorting test, verbal fluency, and motor and graphic sequences. ${ }^{17}$ The Beck Depression Inventory was used to assess depression. Adverse events and non-planned visits or hospitalisations related to surgery or STN stimulation were noted over l year after surgery. Quality of life was assessed using the Parkinson's Disease Quality of

Abbreviations: PD, Parkinson's disease; PDQL-37, Parkinson's Disease Quality of Life Questionnaire; STN, subthalamic nucleus; UPDRS, Unified Parkinson's Disease Rating Scale 


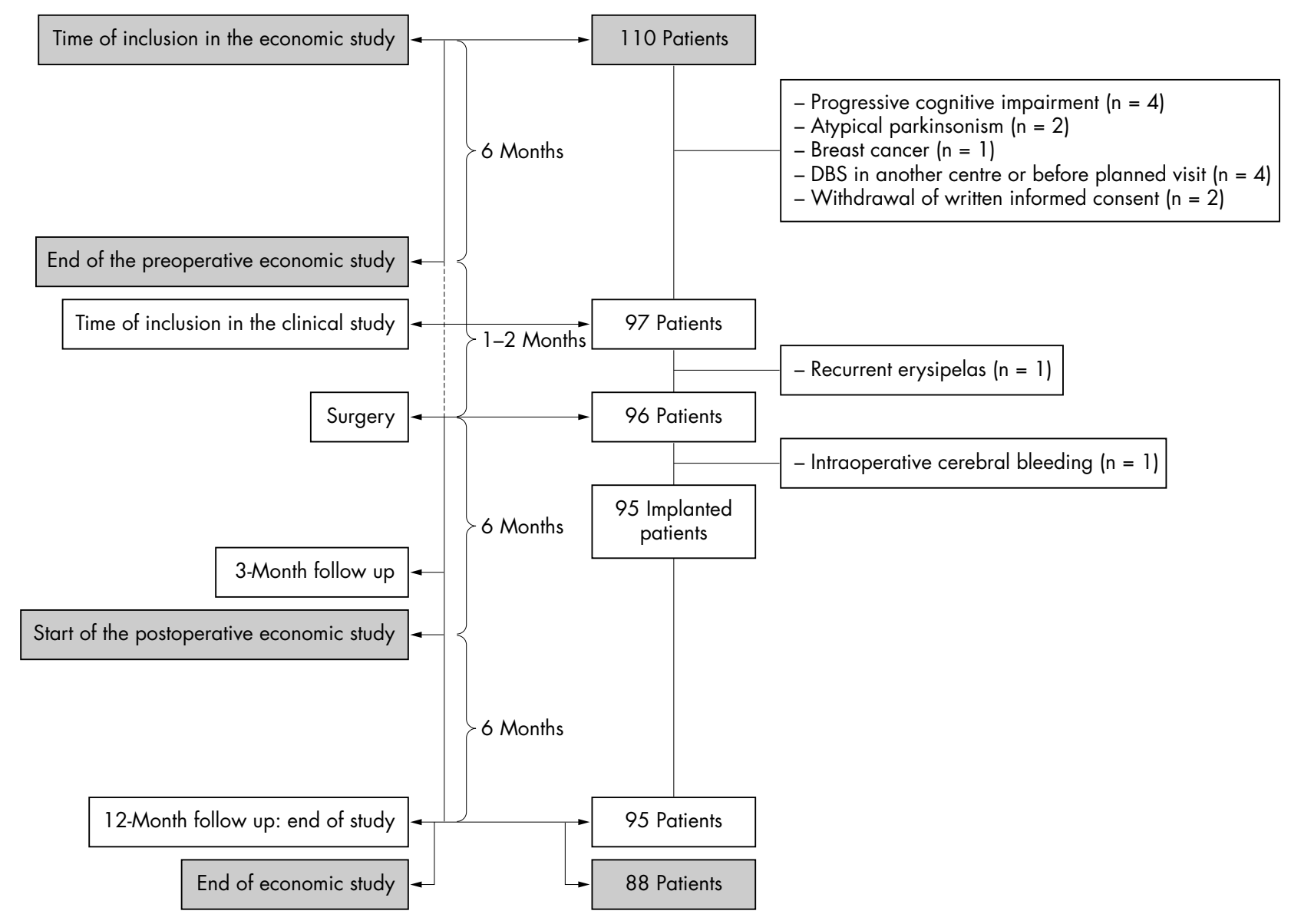

Figure 1 Study design.

Life Questionnaire (PDQL-37) validated for use in French patients. ${ }^{19}$

\section{Surgical technique}

Implantation of the electrodes was performed bilaterally in one session under local anaesthesia, according to the practice of each centre. In all centres, the STN was identified with intraoperative stimulations, using one to five microelectrodes; microrecordings were also used in all but one centre. $^{20-23}$ A chronic electrode with four contacts $1.5 \mathrm{~mm}$ long and $0.5 \mathrm{~mm}$ apart (contact 0 distal to contact 3 proximal; DBS-3389, Medtronic, Minneapolis, MN, USA) was implanted and secondarily connected to a neurostimulator (two single channel Itrel II in $\mathrm{n}=39$ patients or one dual channel Kinetra in $n=56$ patients; Medtronic). The placement of the electrodes was checked by T2 weighted MRI performed before implantation of the neurostimulator and also by stereotactic $\mathrm{x}$ rays in two centres. ${ }^{20}$

\section{Electrical settings}

Chronic parameters of STN stimulation and daily doses of antiparkinsonian drugs were progressively and concomitantly adjusted according to guidelines. ${ }^{24}$

\section{Economic evaluation}

During both 6 month periods of observation, resources use data related to the patients' care and including hospitalisations, outpatient visits, auxiliary care, and antiparkinsonian medication, were collected monthly from individual questionnaires. Healthcare expenditures which occurred within the first 6 postoperative months were included in the cost of the procedure as the patient's global state was not yet stable. Medical consultations and auxiliary care related to PD were valued at their national costs. Hospitalisation costs were estimated from the national Diagnosis Related Group database. Medication costs were determined from the national formulary list. The cost of the procedure included

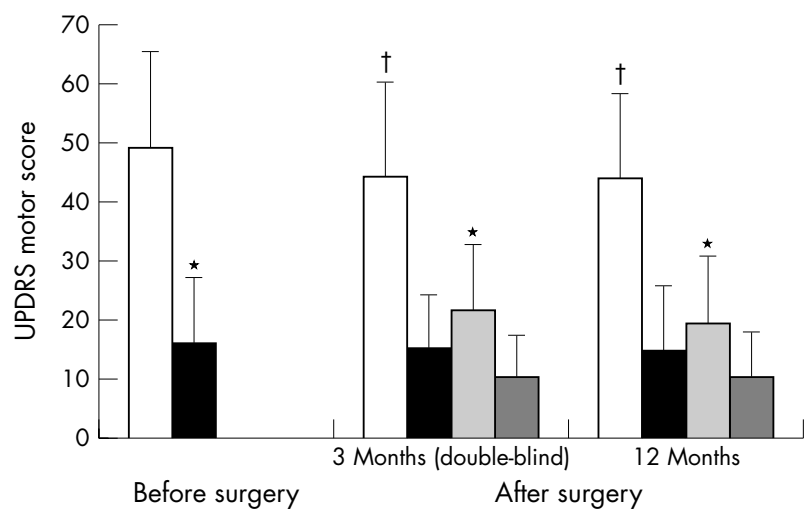

Figure 2 Motor examination score (UPDRS part III, mean \pm SD) in the off-medication and on-medication conditions before $(n=97)$ and 3 (double blind evaluation) and 12 months after surgery $(n=95)$. White bars: off medication and off stimulation; black bars: on medication and off stimulation; light grey bars: off medication and on stimulation; dark grey bars: on medication and on stimulation. ${ }^{*} p<0.0001$ for the comparison with the off medication and off stimulation condition at the same time of follow up; $\uparrow p<0.0001$ for the comparison with the preoperative off-medication score. 


\begin{tabular}{|lr|}
\hline $\begin{array}{l}\text { Table } 1 \text { Characteristics of patients before surgery } \\
(\mathrm{n}=97)\end{array}$ & \\
\hline Patient characteristics & Value \\
\hline Sex & 65 \\
Male $(\mathrm{n})$ & 32 \\
Female $(\mathrm{n})$ & $57 \pm 8$ \\
Age at surgery (mean \pm SD, years) & $43 \pm 9$ \\
Age at onset of PD (mean \pm SD, years) & $14 \pm 5$ \\
Duration of PD (mean \pm SD, years) & $13 \pm 4$ \\
Duration of levodopa therapy (mean \pm SD, years) & $6 \pm 4$ \\
Duration of levodopa induced dyskinesias & \\
(mean $\pm S D$, years) & \\
\hline
\end{tabular}

a 4-5 day stay in hospital for confirmation of surgical indication, surgery, material, check ups, and all inpatient or outpatient visits related to stimulator parameter adjustment required over a 1 year period. The perspective was that of health insurance. Currencies were converted at the rates on 1 January $2000(€ 1=$ US\$1.0053).

\section{Statistical analysis}

The primary outcome measures were the scores on part III (motor examination) of the UPDRS in the off-medication and on-stimulation conditions at 12 month follow up, motor evaluation at 3 month follow up, the health related costs of the procedure, and the scores of the PDQL-37. The secondary measures were the other subscores of the UPDRS, including parts I (mentation and behaviour) and II (activities of daily living), items 32 and 33 of part IV (dyskinesias duration and disability, maximal score 8), part VI (Schwab and England Activities of Daily Living Scale, progressive loss of independence if score $\leqslant 70 \%$ ), neuropsychological tests, and levodopa equivalent daily doses. ${ }^{25}$ Descriptive values were analysed by repeated measures analysis of variance. We used a backward stepwise linear regression analysis to determine predictive factors of motor scores after STN stimulation. The following factors were tested as predictors of the 12 month onstimulation off-medication motor score: age, sex, duration of disease, preoperative off- and on-medication UPDRS motor scores, and scores of cognition and depression scales. Since axial symptoms are known to be less sensitive to STN stimulation and can even worsen, in particular speech, we performed a logistic regression to determine potential predictive factors of axial symptom subscores (speech (UPDRS III, item 18) and postural stability (UPDRS III, item 30)). ${ }^{726}$ We used a paired Student's $t$ test for the comparison between the pre- and post-operative scores of the quality of life scales and healthcare costs. The statistical analysis was by intention to treat in the 96 patients who underwent

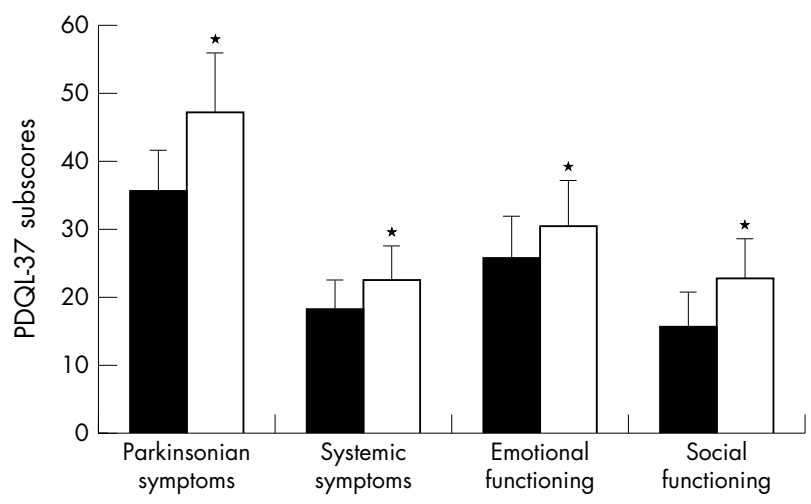

Figure 3 Subscores of the Parkinson's Disease Quality of Life Questionnaire (PDQL-37) before and 12 months after surgery. Black bars: before surgery; white bars: 12 months after surgery. ${ }^{*} p<0.001$ for the comparison with the preoperative score. The total score ranged from 0 (worst) to 185 (best), encompassing four subscores (parkinsonian symptoms: 70 ; systemic symptoms: 35 ; emotional symptoms: 45 ; social symptoms: 35$)$.

surgery and was performed with the Im and Ime procedures of S-PLUS software (Mathsoft Engineering and Education, Cambridge, MA, USA). Results are expressed as mean $\pm \mathrm{SD}, t$ value, and $p$ value. To correct for the number of comparisons and to avoid a type I error, a p value of 0.005 was considered to indicate statistical significance.

\section{RESULTS}

The study was conducted between November 1998 and March 2002. Of 110 selected PD patients, 97 were included in the clinical study and 95 were chronically stimulated (fig 1).

\section{Clinical results}

The clinical characteristics of the patients at baseline are reported in table 1 . In the off-medication condition, the mean UPDRS motor score was $49.2 \pm 16.4$ before surgery, but significantly decreased to $19.4 \pm 11.5$ at the 12 month follow up in the on-stimulation condition (fig 2). At the 3 month follow up, the double blind off-medication motor score was $44 \pm 16$ without stimulation and $21.7 \pm 11.3$ with stimulation (fig 2). Self evaluation of the stimulation condition was available for 72 patients. On the first day of randomisation, 14 patients guessed incorrectly (10 thought they were off although they were on, and four thought the opposite). Examiners made errors in eight patients. All patients and examiners were correct on the second day of randomisation and corrected their initial error.

Table 2 Results of neuropsychological tests before and after surgery

\begin{tabular}{lccc}
\hline & \multicolumn{2}{l}{ Score (mean \pm SD) } & \\
\cline { 2 - 3 } & Before surgery & $\mathbf{3}$ Month follow up & $\mathbf{1 2}$ Month follow up \\
\hline Mattis Dementia Rating Scale (maximal score 144) & $136.3 \pm 5.8$ & $135.0 \pm 9.5$ & $136.1 \pm 7.3$ \\
Grober and Buschke Verbal Learning Test & $26.2 \pm 6.2$ & $26.9 \pm 7.7$ & $28.3 \pm 7.1^{* *}$ \\
Free recall (maximal score 48) & $45.4 \pm 4.3$ & $45.3 \pm 4.7$ & $46.4 \pm 2.7^{*}$ \\
Total recall (maximal score 48) & $15.6 \pm 0.9$ & $15.6 \pm 0.9$ & $15.7 \pm 0.9$ \\
Delayed recall (maximal score 16) & $10.1 \pm 2.9$ & $10.3 \pm 3.2$ & $10.5 \pm 2.6$ \\
Delayed free recall (maximal score 16) & $15.8 \pm 4.7$ & $16.9 \pm 4.2^{*}$ & $16.7 \pm 4.1^{*}$ \\
Wisconsin Card Sorting Test (maximal score 20) & $11.5 \pm 7.0$ & $7.0 \pm 4.9^{* *}$ & $7.2 \pm 2.1^{* *}$ \\
Beck Depression Inventory (maximal score 59) & $8.1 \pm 2.0$ & $7.2 \pm 2.2^{* *}$ & $7.9 \pm 2.5$ \\
Lexical Fluency (maximal score 10) & $7.8 \pm 2.6$ & $8.0 \pm 2.8$ & $8.7 \pm 2.2^{*}$ \\
Graphic Series (maximal score 10) & $8.0 \pm 3.2$ & $8.3 \pm 2.8$ & $40.5 \pm 7.2$ \\
Motor Series (maximal score 10) & $39.6 \pm 9.5$ & $40.6 \pm 9.2$ & \\
Global Frontal Score (maximal score 50) & & \\
\hline * $\mathrm{p}<0.002$ compared with the preoperative score; ** $\mathrm{p}<0.0001$ compared with the preoperative score. & \\
\hline
\end{tabular}


Table 3 Electrical parameters of bilateral STN stimulation

\begin{tabular}{lr}
\hline Electrical parameters & Value \\
\hline Type of stimulation ( $\mathrm{n}=$ number of electrodes) & \\
Monopolar & 187 \\
1 contact & 155 \\
2 contacts & 29 \\
3 contacts & 3 \\
Bipolar 2 contacts & 3 \\
Rate $(n=$ number of electrodes) & 3 \\
$<130 \mathrm{~Hz}$ & 181 \\
$130 \mathrm{~Hz} \leqslant$ rate $\leqslant 185 \mathrm{~Hz}$ & 6 \\
$>185 \mathrm{~Hz}$ & 136 \\
Pulse width ( $\mathrm{n}=$ number of electrodes) & 54 \\
$60 \mu \mathrm{s}$ & $2.77 \pm 0.52$ \\
$90 \mu \mathrm{s}$ & \\
Voltage $(\mathrm{V}$, mean $\pm S D)$ &
\end{tabular}

The duration of the on-period without dyskinesias increased from $5.5 \pm 3.4 \mathrm{~h}$ daily before surgery to $10.6 \pm 5.0 \mathrm{~h}$ daily 12 months after surgery $(\mathrm{p}<0.0001)$. The dyskinesia score decreased from $4.07 \pm 1.83$ to $1.03 \pm 1.35$ at the 12 month follow up $(\mathrm{p}<0.0001)$.

\section{Disability and activities of daily living}

The mean score of the Schwab and England scale in the offmedication condition was $42.1 \pm 19.3$ before surgery and improved to $74.8 \pm 18.8$ at the 12 month follow up $(p<0.0001)$. Before surgery, 85 of the 97 patients were dependent on a caregiver for some activities of daily living in the off-medication condition, whereas only 30 were similarly dependent at the 12 month follow up. In off-medication condition, the UPDRS part II score decreased from $26.8 \pm 6.9$ before surgery to $13.8 \pm 7.3$ at the 12 month follow up $(p<0.0001)$. No change in this score was noted in the onmedication condition. According to the home diaries, sleep duration significantly increased from $7.8 \pm 1.7 \mathrm{~h}$ before surgery to $8.6 \pm 1.8 \mathrm{~h} 12$ months after electrode implantation $(\mathrm{p}<0.0001)$.

\section{Quality of life}

The mean total score of the PDQL-37 scale improved from $95.1 \pm 17.2$ to $120.9 \pm 23.8(\mathrm{p}<0.0001)$. All subscores significantly increased (fig 3 ).

\section{Behaviour and cognitive functions}

The total UPDRS part I score increased from $1.7 \pm 1.5$ before surgery to $2.4 \pm 1.9$ at the 12 month follow up $(\mathrm{p}<0.0001)$. This increase was mainly related to worsening in the motivation score (item 4) from $0.3 \pm 0.5$ before surgery to $0.8 \pm 0.9$ at the 12 month follow up $(\mathrm{p}<0.0001)$. A motivation



Figure 4 Number of non-planned visits and hospitalisations over 12 months after surgery. Black bars: outpatient visits; white bars: hospitalisations.

subscore higher than 2/4 was found in one patient before surgery and in 22 patients at the 12 month follow up. Changes in cognition and mood after surgery were generally minor (table 2). At the 3 month follow up, the Mattis Dementia Rating Scale score declined in seven patients by more than 1.5 SD from the whole group baseline value. Four of these patients were older than 65 and had a preoperative Mattis Dementia Rating Scale score less than the mean score of all participating patients. None of these four patients had a worsening in quality of life according to their scoring in the PDQL-37.

\section{Medication and electrical treatment}

Table 3 shows the electrical parameters of STN stimulation and table 4 antiparkinsonian medications before and after surgery. The active contacts were either number 1 or 2 in $78 \%$ of the electrodes. Postoperative checking of electrode placement showed that the mean coordinates of the most distal contact of the electrodes were $9.4 \pm 1.7 \mathrm{~mm}$ anterior to the posterior commissure, $11.0 \pm 1.6 \mathrm{~mm}$ lateral to midline, and $6.3 \pm 1.4 \mathrm{~mm}$ below the bicommissural line.

\section{Predictive factors}

After discarding factors with low predictive power, we found that the best predictive factor for surgery induced benefit was a low preoperative on-medication motor score. This means that the better the 12 month postoperative on-stimulation off-medication motor score, the better the preoperative motor score under levodopa (one centre had a different formula from the others). We could not find any predictive factor for speech and postural stability subscores.

Table 4 Antiparkinsonian drugs before and after surgery

\begin{tabular}{|c|c|c|}
\hline Medication & Before surgery & $\begin{array}{l}12 \text { months } \\
\text { after surgery }\end{array}$ \\
\hline Levodopa ( $\mathrm{n}=$ number of patients) & 6 & 25 \\
\hline Dopamine agonist ( $\mathrm{n}=$ number of patients) (sc apomorphine) & $2[1]$ & $23[0]$ \\
\hline Levodopa+dopamine agonist ( $\mathrm{n}=$ number of patients) (sc apomorphine) & $89[26]$ & $41[0]$ \\
\hline Apomorphine repeated injections ( $\mathrm{n}=$ number of patients) & 23 & - \\
\hline Unitary dose $(\mathrm{mg})$ (mean \pm SD) (number of injections/day) & $11 \pm 4[1-7]$ & - \\
\hline Apomorphine continuous infusion ( $n=$ number of patients) & $\begin{array}{l}1 \\
-14\end{array}$ & - \\
\hline Flow rate $/ \mathrm{h}(\mathrm{mg})(\mathrm{mean} \pm \mathrm{SD})$ (number of hours/day) & $5 \pm 2[12-24]$ & - \\
\hline No drug ( $n=$ number of patients) & 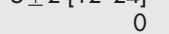 & 6 \\
\hline Total ( $n=$ number of patients) & 97 & 95 \\
\hline Levodopa equivalent daily dose $(\mathrm{mg})($ mean \pm SD) & $1240 \pm 586$ & $506 \pm 429^{* *}$ \\
\hline
\end{tabular}


Table 5 Cost of 6 months' care per PD patient before and after STN stimulation

\begin{tabular}{|c|c|c|c|c|c|c|}
\hline \multirow[b]{2}{*}{ Cost breakdown } & \multicolumn{2}{|l|}{ Preoperative } & \multicolumn{2}{|l|}{ Postoperative } & \multirow{2}{*}{$\frac{\text { Differential }}{\text { Mean } \pm \text { SD }}$} & \multirow[b]{2}{*}{$p$ value } \\
\hline & Mean \pm SD & Median (quartiles) & Mean \pm SD & Median (quartiles) & & \\
\hline Hospitalisations linked to PD & $1334 \pm 2314$ & $0(0-1956)$ & $494 \pm 1899$ & $0(0-0)$ & $840 \pm 2188$ & 0.0005 \\
\hline Consultations & $203 \pm 175$ & 151 (91-293) & $153 \pm 128$ & $129(51-221)$ & $50 \pm 167$ & 0.0065 \\
\hline Auxiliary care & $186 \pm 229$ & $161(0-275)$ & $181 \pm 249$ & $109(0-218)$ & $5 \pm 258$ & NS \\
\hline Antiparkinsonian medication & $8122 \pm 4040$ & 7986 (5294-10 317) & $624 \pm 521$ & $454(222-900)$ & $7498 \pm 3865$ & $<0.0001$ \\
\hline Other medication & $243 \pm 251$ & $167(64-347)$ & $220 \pm 279$ & $136(8-337)$ & $23 \pm 22$ & NS \\
\hline Total cost & $10087 \pm 4887$ & 10049 (6595-12 831) & $1673 \pm 2111$ & $1122(703-1869)$ & $8415 \pm 4438$ & $<0.0001$ \\
\hline
\end{tabular}

\section{Additional visits and adverse events}

We recorded 520 visits in addition to the planned 3 and 12 month follow-up visits, including 121 hospitalisations for 57 patients and 399 outpatient visits for 80 patients, mainly within the first 6 months of follow up (fig 4). Seventy nine per cent of all additional visits were related to worsening of parkinsonism or stimulation induced dyskinesias and concerned 82 patients. These symptoms always improved after the electrical stimulation parameters were adjusted.

Five patients developed an intracerebral haematoma during electrode implantation. This was responsible for permanent left hemiparesis in one patient, in whom a chronic electrode was not implanted, and permanent frontal lobe dysfunction and worsening in the Mattis Dementia Rating Scale score in a second patient. The three other patients developed hemiparesis or confusion with complete remission within 1 week. Two patients became confused during electrode implantation but were back to normal within the following postoperative days. In one patient the electrode migrated 3 months after the operation and was reimplanted. Infection of one extension lead occurred in one patient, necessitating the removal of all implanted material and general antibiotherapy. The patient was operated on again 9 months later without sequelae. Two patients caught pneumonia in the immediate postoperative period. Cognitive and behavioural adverse events that led to an additional visit involved depression in nine patients, psychosis in two patients, hypomania in five patients, and apathy in two patients. At the end of the study, the two patients with sequelae following intracerebral haematoma had adverse events with ongoing consequences for daily living.

\section{Economic evaluation}

Complete data for the economic study were available for 88 of the 96 patients selected for surgery. Eight patients refused to fill in charts of health related costs. One of these patients was not implanted because of intracerebral haematoma; the

\begin{tabular}{lc}
\hline \multicolumn{2}{l}{ Table 6 Cost of procedure per patient } \\
\hline Cost breakdown & Mean cost per patient \\
\hline Before surgery & 2204 \\
$\quad$ Confirmation of indication & 27625 \\
Time of surgery & \\
$\quad$ Hospitalisation for surgery (including & \\
cost of equipment) & \\
After surgery & \\
Planned visits (over 1 year) & 1847 \\
$\quad$ Hospitalisations & 1549 \\
$\quad 3$ month follow up & 2145 \\
$\quad$ 12 month follow up & 392 \\
$\quad$ Outpatient visits ( $n=2)$ & 1142 \\
Non-planned visits (over 1 year) & 36904 \\
$\quad$ Adverse events linked to surgery & \\
Adjustment of electrical parameters & \\
Total cost & \\
\hline Values are in euros (€). &
\end{tabular}

others did not significantly differ from the whole group in terms of inclusion criteria and outcome. We recorded 41 hospitalisations related to $\mathrm{PD}$ for 30 patients and 613 outpatient visits for 87 patients within the preoperative 6 month period of observation and 12 hospitalisations for 10 patients and 504 outpatient visits for 79 patients within the postoperative 6 month period of observation.

The total 6 month cost decreased from $€ 10087 \pm 4887$ before surgery to $€ 1673 \pm 2111$ after surgery (table 5 ). The cost of the procedure was estimated at $€ 36904$ per patient, including a stay in hospital of 4-5 days for confirmation of surgical indication, hospitalisation for surgery (18-31 days), cost of equipment, and cost of all consultations or hospitalisations for postoperative adjustments of the stimulation parameters and cost of drug therapy during the first postoperative year (table 6).

\section{DISCUSSION}

We conducted a prospective, multicentre, economic, and clinical study of bilateral STN stimulation in PD patients with levodopa induced motor complications. Off-period symptoms greatly improved in agreement with previously reported studies. ${ }^{5-8}{ }^{27}$ However, 30 of the 95 stimulated patients still required at least some help for activities of daily living according to the Schwab and England scale. At the 3 month follow up, the blinded off-medication UPDRS motor score was improved by $51 \%$ and the non-blinded evaluation at the 12 month follow up was improved by $57 \%$. The magnitude of motor changes induced by STN stimulation makes a double blind condition difficult to apply, as motor improvement is the only effect that allows a patient guess at the stimulation condition. This might explain why almost all patients correctly guessed the stimulation condition. Three other double blind studies of STN stimulation reported almost similar improvement in motor function. ${ }^{6} 828$

The patients operated upon had a highly levodopa responsive $\mathrm{PD}$ which has been shown to be the main inclusion criterion for positive outcome after surgery. ${ }^{12} 2930$ We found that the best predictive factor for surgery induced benefit was a low preoperative on-period motor score, whatever its severity during off periods. Therefore, the most suitable candidates for STN stimulation should exhibit an excellent on-period motor function, even if off-period motor disability or levodopa induced dyskinesias are severe. In one centre the postoperative on-stimulation motor score was worse than in the others. We were unable to determine the reasons for this difference since the patients' characteristics were similar in all centres and postoperative imaging showed that, in all cases, the active contact corresponded to the theoretical area of the STN. ${ }^{20}{ }^{31}$ The degree of motor benefit could be related to this homogeneous targeting checked by imaging in all patients.

Consistent with previously published data, no cognitive impairment was reported in most patients after surgery, except deterioration in verbal fluency. ${ }^{32-34}$ The seven patients whose cognitive functions deteriorated were older than 
average or had lower preoperative cognitive performance, in keeping with other reports. ${ }^{5635}$ Two of these patients developed cognitive impairment due to intracerebral complications related to electrode implantation, with ongoing consequences in daily living. A worsening in motivation was observed in some patients and might be responsible for an apathetic state; however, only two patients required an additional visit due to this adverse effect. Since apathy can be improved by an increase in dopaminergic treatment, it might be the consequence of too great a decrease in postoperative dopaminergic medication. The proportion of severe complications after STN stimulation is in keeping with previous studies and inherent to any stereotactic neurosurgical procedure with implantation of material. ${ }^{636} 37$

The benefit of STN stimulation on motor function allowed a major improvement in all aspects of quality of life, especially the social functioning subscale, as already reported with this procedure. ${ }^{938-40}$

The global cost of STN stimulation in patients with PD, including material, personnel, hospital stays, and all followup visits, amounted to $€ 36904$. This total is higher than that previously reported in another prospective study of the effects of STN stimulation on health status and healthcare resources conducted in $16 \mathrm{PD}$ patients. ${ }^{41}$ The cost of equipment, medication at baseline, and the mean duration of stay in hospital were similar in both reports. In our study, after discharge from hospital, additional visits were required to adjust electrical settings. The distance the participating patients lived from the four centres may explain why most needed to stay a few days in hospital for these adjustments. These visits may partly account for the higher cost of the procedure obtained in our study, but the hospital cost is also higher than that of the German study. This cost is determined by the national Diagnosis Related Group database and may differ from that in other countries and thus influence interpretation of the results. The improvement in motor function after STN stimulation was similar in both studies with considerable impact on self care ability and quality of life, but the decrease in dopaminergic medication costs after surgery was greater in our study. This difference might be explained by the high number of patients receiving subcutaneous apomorphine in our study, all of whom discontinued this treatment after STN implantation, whereas no patient with apomorphine participated in the other study. Given the savings in healthcare expenditure obtained in a 6 month period, the cost of the procedure would allow a return on investment over 2.2 years. Thus, we may consider that STN stimulation is cost effective, confirming previously published theoretical models estimating the costs of this technique. ${ }^{13} 15$

However, some limitations of our study have to be addressed. Estimation of the cost of the procedure and savings after STN implantation did not consider the additional costs from neurosurgical complications in one patient for whom no economic data were available. The assumed increase in healthcare expenditure for this single case would have had a minor impact on the savings for the total group of patients. Calculation of the costs of the procedure were only based on direct medical costs and did not include indirect costs such as loss of productivity due to early retirement or care provided by families, which have been proved to have a heavy impact on health resources. ${ }^{10}$ We did not take into account the cost of the replacement of the neurostimulator, estimated at $€ 15000$ every 5 years. $^{724}$ Our study was conducted over a 1 year period in relatively young patients and we did not consider the possible long term occurrence of disabling symptoms such as dementia, postural instability, speech deficit, and dysautonomia. These symptoms may be responsible for an increase in scores of the
UPDRS activities of daily living scale while on stimulation and a higher risk of institutionalisation, substantially contributing to health expenditure. ${ }^{2}$ However, it has been demonstrated that nursing home admissions were less frequent in patients who have had STN implantation compared to medically treated patients. ${ }^{15}$ Since the major benefit on motor function is largely maintained over 5 years, the results of this study are valuable at least for this period of time; further long term studies are warranted. ${ }^{7}$

\section{ACKNOWLEDGEMENTS}

We are indebted to Vicki Laing-Bernard for English assistance.

\section{CONTRIBUTORS}

Doctor Pollak had full access to all the data in the study and takes responsibility for the integrity of the data and the accuracy of the data analysis. Valérie Fraix participated in the recruitment, clinical evaluation, and follow up of the participants in the study, in data interpretation, and in the writing of the paper. Jean-Luc Houeto contributed to the clinical evaluation and follow up of the patients and to the writing of the paper. Christelle Lagrange was responsible for the on-site management of the study and data collection, and participated in data statistical analysis and interpretation and in the writing of the paper. Pierre Krystkowiak contributed to the recruitment and follow up of the participants in the study and to the writing of the paper. Dominique Guehl, Marie-Laure Welter, Luc Defebvre, and Valérie Mesnage participated in the study as clinical investigators. Claire Ardouin contributed to the neuropsychological evaluation of the patients. Alain Rougier, Serge Blond, Alim-Louis Benabid, and Philippe Cornu performed the electrode implantation in the patients. Pierre Burbaud, Bernard Bioulac, and Alain Destée participated in the recruitment of the patients. Claude Le Pen designed and implemented the economic study. Frédérique Maurel supervised economic data management and participated in the interpretation of the data and in the writing of the paper. Marie Ligier carried out the statistical analysis of the economic data. Pierre Pollak was the main investigator, designed the study, participated in the recruitment, clinical evaluation and follow up of the participants, and in the interpretation of the results and the writing of the paper.

\section{Authors' affiliations \\ V Fraix, C Lagrange, C Ardouin, A-L Benabid, P Pollak, Department of Neurology and Neurosurgery, Grenoble University Hospital and INSERM U318, Joseph Fourier University, Grenoble, France J-L Houeto, M-L Welter, V Mesnage, P Cornu, Federation of Neurology, Clinical Investigation Centre, La Pitié-Salpétrière Hospital, Paris, France C Le Pen, F Maurel, M Ligier, CLP-Santé, Paris, France \\ P Krystkowiak, L Defebvre, S Blond, A Destée, Department of Neurology and Neurosurgery, Lille University Hospital, Lille, France D Guehl, A Rougier, P Burbaud, B Bioulac, Department of Neurology and Neurosurgery, Bordeaux University Hospital, Bordeaux, France}

This work was supported by the Fondation pour la Recherche Médicale (FRM, Paris, France) (financial support, Action Santé 2000), INSERM U318 (Grenoble, France), the Clinical Investigation Centre (CIC, Paris, France), and the University Hospital of Grenoble, France.

Competing interests: none declared. The sponsors of the study had no role in study design, data collection, data analysis, data interpretation, or in the writing of the paper.

Members of the SPARK Study Group: neurologists: Grenoble, France: Valérie Fraix, Elena Moro, Pierre Pollak, Nadège Van Blercom, Jing Xie; Paris, France: Yves Agid, Anne-Marie Bonnet, Philippe Damier, Jean-Luc Houeto, Valérie Mesnage, Marie Vidailhet, Marie-Laure Welter; Lille, France: Luc Defebvre, Alain Destée, Pierre Krystkowiak, Nawal Waucquier; Bordeaux, France: Bernard Bioulac, Pierre Burbaud, Dominique Guehl, Alain Lagueny, François Tison; neurosurgeons: Grenoble, France: Alim-Lovis Benabid, Stephan Chabardes, Adnan Koudsie; Paris, France: Philippe Cornu, Soledad Navarro; Lille, France: Serge Blond, Gustavo Touzet; Bordeaux, France: Emmanuel Cuny, Alain Rougier; intraoperative neurophysiology: Grenoble, France: Abdelhamid Benazzouz; Paris, France: Bernard Pidoux; Lille, France: François Cassim; Bordeaux, France: Christian Gross; magnetic resonance imaging: Grenoble, France: Sylvie Grand, Jean-François Le Bas; Paris, France: Didier Dormont; Lille, France: Jean-Pierre Pruvo, Christine Delmaire; Bordeaux, France: Vincent Dousset; neuropsychological 
evaluation: Grenoble, France: Claire Ardouin, Hélène Klinger; Paris, France: Bernard Pillon; Lille, France: Kathy Dujardin; Bordeaux, France: Sandra Machado; biostatistics: INRIA, Grenoble, France: Gilles Celeux, Christian Lavergne, Virginie Roy; economic study: CLP-Santé, Paris, France: Claude Le Pen, Marie Ligier, Frédérique Maurel; Clinical Investigation Centre, Paris, France: Laurence Vigil; study supervision: Grenoble, France: Christelle Lagrange.

\section{REFERENCES}

1 Chrischilles EA, Rubenstein LM, Voelker MD, et al. The health burdens of Parkinson's disease. Mov Disord 1998;13(3):406-13.

2 LePen C, Wait S, Moutard-Martin F, et al. Cost of illness and disease severity in a cohort of French patients with Parkinson's disease. Pharmacoeconomics 1999; 16(1):59-69.

3 Kurtzke JF. The current neurologic burden of illness and injury in the United States. Neurology 1982;32(11):1207-14.

4 Rubenstein LM, Chrischilles EA, Voelker MD. The impact of Parkinson's disease on health status, health expenditures, and productivity. Estimates from the National Medical Expenditure Survey. Pharmacoeconomics 1997; 12(4):486-98.

5 Limousin P, Krack P, Pollak P, et al. Electrical stimulation of the subthalamic nucleus in advanced Parkinson's disease. N Engl J Med 1998;339(16): 1 105-11

6 The Deep-Brain Stimulation for Parkinson's Disease Study Group. Deepbrain stimulation of the subthalamic nucleus or the pars interna of the globus pallidus in Parkinson's disease. N Engl J Med 2001;345(13):956-63.

7 Krack P, Batir A, Van Blercom N, et al. Five-year follow-up of bilateral stimulation of the subthalamic nucleus in advanced Parkinson's disease. N Engl J Med 2003;349(20): 1925-34

8 Rodriguez-Oroz MC, Zamarbide I, Guridi J, et al. Efficacy of deep brain stimulation of the subthalamic nucleus in Parkinson's disease 4 years after surgery: double blind and open label evaluation. $J$ Neurol Neurosurg Psychiatry 2004;75(10): 1382-5.

9 Volkmann J. Deep brain stimulation for the treatment of Parkinson's disease. J Clin Neurophysiol 2004;21(1):6-17.

10 Findley L, Aujla M, Bain PG, et al. Direct economic impact of Parkinson's disease: a research survey in the United Kingdom. Mov Disord 2003; 18(10): 1139-45.

11 Gage H, Hendricks A, Zhang S, et al. The relative health related quality of life of veterans with Parkinson's disease. J Neurol Neurosurg Psychiatry 2003;74(2): 163-9.

12 Ford B, Winfield L, Pullman SL, et al. Subthalamic nucleus stimulation in advanced Parkinson's disease: blinded assessments at one year follow up. J Neurol Neurosurg Psychiatry 2004;75(9): 1255-9.

13 Mclntosh E, Gray A, Aziz T. Estimating the costs of surgical innovations: the case for subthalamic nucleus stimulation in the treatment of advanced Parkinson's disease. Mov Disord 2003;18(9):993-9.

14 Rubenstein LM, DeLeo A, Chrischilles EA. Economic and health-related quality of life considerations of new therapies in Parkinson's disease. Pharmacoeconomics 2001;19(7):729-52.

15 Tomaszewski KJ, Holloway RG. Deep brain stimulation in the treatment of Parkinson's disease: a cost-effectiveness analysis. Neurology 2001;57(4):663-71.

16 Lang AE, Widner H. Deep brain stimulation for Parkinson's disease: patient selection and evaluation. Mov Disord 2002;17(suppl 3):S94-101.

17 Pillon B. Neuropsychological assessment for management of patients with deep brain stimulation. Mov Disord 2002;17(suppl 3):S1 16-22.

18 Fahn S, Elton RL, and members of UPDRS development committee. Unified Parkinson's disease rating scale. In: Fahn S, Marsden CD, Calne DB, et al. Recent developments in Parkinson's disease. Florham Park, NJ: Mac Millan Health Care Information, 1987:153-63.
19 de Boer AG, Wijker W, Speelman JD, et al. Quality of life in patients with Parkinson's disease: development of a questionnaire. J Neurol Neurosurg Psychiatry 1996;61(1):70-4.

20 Benabid AL, Koudsie A, Benazzouz A, et al. Imaging of subthalamic nucleus and ventralis intermedius of the thalamus. Mov Disord 2002;17/suppl 3):S123-9.

21 Benazzouz A, Breit S, Koudsie A, et al. Intraoperative microrecordings of the subthalamic nucleus in Parkinson's disease. Mov Disord 2002;17/suppl 3):S145-9.

22 Blond S, Touzet G, Krystkowiak P, et al. [Neurosurgical treatment of Parkinson's disease: which technique is best?]. Rev Neurol (Paris) 2000; 156(suppl 2 pt 2):257-69.

23 Pollak P, Krack P, Fraix V, et al. Intraoperative micro- and macrostimulation of the subthalamic nucleus in Parkinson's disease. Mov Disord 2002;17/suppl 3):S155-61.

24 Volkmann J, Herzog J, Kopper F, et al. Introduction to the programming of deep brain stimulators. Mov Disord 2002;17(suppl 3):S181-7.

25 Lozano AM, Lang AE, Galvez-Jimenez N, et al. Effect of GPi pallidotomy on motor function in Parkinson's disease. Lancet 1995;346(8987): 1383-7.

26 Rodriguez-Oroz MC, Obeso JA, Lang AE, et al. Bilateral deep brain stimulation in Parkinson's disease: a multicentre study with 4 years follow-up. Brain 2005; 128(pt 10):2240-9.

27 Herzog J, Volkmann J, Krack P, et al. Two-year follow-up of subthalamic deep brain stimulation in Parkinson's disease. Mov Disord 2003;18(1 1):1332-7.

28 Kumar R, Lozano AM, Kim YJ, et al. Double-blind evaluation of subthalamic nucleus deep brain stimulation in advanced Parkinson's disease. Neurology 1998;51(3):850-5.

29 Charles PD, Van Blercom N, Krack P, et al. Predictors of effective bilateral subthalamic nucleus stimulation for PD. Neurology 2002;59(6):932-4.

30 Welter ML, Houeto JL, Tezenas du Montcel S, et al. Clinical predictive factors of subthalamic stimulation in Parkinson's disease. Brain 2002;125(pt 3):575-83.

31 Yelnik J, Damier P, Demeret S, et al. Localization of stimulating electrodes in patients with Parkinson disease by using a three-dimensional atlas-magnetic resonance imaging coregistration method. J Neurosurg 2003;99(1):89-99.

32 Ardouin C, Pillon B, Peiffer E, et al. Bilateral subthalamic or pallidal stimulation for Parkinson's disease affects neither memory nor executive functions: a consecutive series of 62 patients. Ann Neurol 1999;46(2):217-23.

33 Dujardin K, Defebvre L, Krystkowiak P, et al. Influence of chronic bilateral stimulation of the subthalamic nucleus on cognitive function in Parkinson's disease. J Neurol 2001;248(7):603-11.

34 Jahanshahi M, Ardouin CM, Brown RG, et al. The impact of deep brain stimulation on executive function in Parkinson's disease. Brain 2000;123/pt 6): 1142-54.

35 Saint-Cyr JA, Trepanier LL, Kumar R, et al. Neuropsychological consequences of chronic bilateral stimulation of the subthalamic nucleus in Parkinson's disease. Brain 2000;123(pt 10):2091-108.

36 Pollak P, Fraix V, Krack P, et al. Treatment results: Parkinson's disease. Mov Disord 2002;17(suppl 3):S75-83.

37 Lyons KE, Wilkinson SB, Overman J, et al. Surgical and hardware complications of subthalamic stimulation: a series of 160 procedures. Neurology 2004;63(4):612-6.

38 Lagrange $E$, Krack P, Moro E, et al. Bilateral subthalamic nucleus stimulation improves health-related quality of life in PD. Neurology 2002;59(12):1976-8.

39 Martinez-Martin P, Valldeoriola F, Tolosa E, et al. Bilateral subthalamic nucleus stimulation and quality of life in advanced Parkinson's disease. Mov Disord 2002;17(2):372-7

40 Just H, Ostergaard K. Health-related quality of life in patients with advanced Parkinson's disease treated with deep brain stimulation of the subthalamic nuclei. Mov Disord 2002;17(3):539-45.

41 Spottke EA, Volkmann J, Lorenz D, et al. Evaluation of healthcare utilization and health status of patients with Parkinson's disease treated with deep brain stimulation of the subthalamic nucleus. J Neurol 2002;249(6):759-66. 